\title{
Interleukin-6 and C-reactive protein as prognostic biomarkers in metastatic colorectal cancer
}

\author{
Maria Thomsen ${ }^{1,2}$, Christian Kersten ${ }^{3}$, Halfdan Sorbye ${ }^{4}$, Eva Skovlund ${ }^{5}$, Bengt \\ Glimelius $^{6}$, Per Pfeiffer ${ }^{7}$, Julia S. Johansen ${ }^{8}$, Elin H. Kure ${ }^{9}$, Tone Ikdahl' ${ }^{10}$, Kjell \\ Magne Tveit ${ }^{1,2,11}$, Thoralf Christoffersen ${ }^{12}$, Tormod Kyrre Guren ${ }^{1,11}$ \\ ${ }^{1}$ Department of Oncology, Oslo University Hospital, Oslo, Norway \\ ${ }^{2}$ Institute of Clinical Medicine, University of Oslo, Oslo, Norway \\ ${ }^{3}$ Department of Oncology, Southern Hospital Trust, Kristiansand, Norway \\ ${ }^{4}$ Department of Oncology, Haukeland University Hospital, University of Bergen, Bergen, Norway \\ ${ }^{5}$ Department of Public Health and General Practice, Norwegian University of Science and Technology, Trondheim, Norway \\ ${ }^{6}$ Department of Immunology, Genetics and Pathology, Uppsala University, Uppsala, Sweden \\ ${ }^{7}$ Department of Oncology, Odense University Hospital, Institute of Clinical Research, University of Southern Denmark, \\ Odense, Denmark \\ ${ }^{8}$ Department of Oncology, Herlev and Gentofte Hospital, Copenhagen University Hospital, Herlev, Denmark \\ ${ }^{9}$ Department of Cancer Genetics, Institute for Cancer Research, Oslo University Hospital, Oslo, Norway \\ ${ }^{10}$ Akershus University Hospital, Nordbyhagen, Norway \\ ${ }^{11}$ K.G. Jebsen Colorectal Cancer Research Centre, Oslo University Hospital, Oslo, Norway \\ ${ }^{12}$ Department of Pharmacology, Institute of Clinical Medicine, Faculty of Medicine, University of Oslo, Oslo, Norway \\ Correspondence to: Maria Thomsen, email: uxthmg@ous-hf.no
}

Keywords: $m C R C, I L-6, C R P$, prognostic biomarker, survival

Received: May 20, $2016 \quad$ Accepted: September 19, 2016

Published: October 21, 2016

\section{ABSTRACT}

Objectives: The aim was to explore the prognostic significance of IL-6 and markers of systemic inflammatory response (SIR), in particular C-reactive protein (CRP), in metastatic colorectal cancer ( $\mathrm{MCRC}$ ) patients, in the total study population and according to RAS and BRAF mutation status.

Results: High levels of pretreatment serum IL-6 or CRP were associated with impaired outcome, in terms of reduced PFS and OS. Patients with low versus high serum IL-6 levels had median OS of 26.0 versus 16.6 months, respectively $(P<0.001)$. Stratified according to increasing CRP levels, median OS varied from 24.3 months to 12.3 months, $(P<0.001)$. IL-6 and CRP levels affected overall prognosis also in adjusted analyses. The effect of IL- 6 was particularly pronounced in patients with $B R A F$ mutation (interaction $P=0.004$ ).

Materials and Methods: IL-6 and CRP were determined in pre-treatment serum samples from 393 patients included in the NORDIC-VII trial, in which patients with $\mathrm{MCRC}$ received first line treatment. The effect of serum IL-6 and CRP on progressionfree survival (PFS) and overall survival (OS) was estimated.

Conclusions: High baseline serum consentrations of IL- 6 or CRP were associated with impaired prognosis in MCRC. IL-6 and CRP give independent prognostic information in addition to RAS and BRAF mutation status. 


\section{INTRODUCTION}

Colorectal cancer (CRC) is worldwide the second most commonly diagnosed cancer in females and the third in males. Almost half of the patients diagnosed with CRC have or will develop distant metastases [1]. Metastatic CRC (mCRC) follows widely differing clinical courses, depending on genetic and non-genetic factors. A large body of evidence indicates that an inflammatory microenvironment is of decisive importance for the progression of tumors and the clinical outcome of cancers [2-6], including CRC [7]. It would be valuable to have easily accessible biomarkers for monitoring of the inflammatory status of the cancer, and several inflammation-based factors have been evaluated for their usefulness as prognostic biomarkers $[6,8,9]$.

While critical mutations are the underlying drivers in oncogenesis [10], interaction between the transformed cells and the microenvironment is necessary for a cancer to evolve, progress, and metastasize [2, 11, 12]. Malignant cells may evade the many innate and adaptive defense mechanisms and eventually give rise to neoplasms, due to their ability to induce immune suppression and to control and redirect the functions of several of the stromal cells, shaping a symbiotic local environment [11] which basically takes the character of an inflammatory reaction, a recognized hallmark of cancer [3, 13]. Although the stroma is the arena for numerous opposing stimulatory and inhibitory mechanisms [14-17], the very existence of the tumor reveals its escape from the host defense, and many lines of evidence strongly suggest that the microenvironment is largely tumor-promoting at all stages of cancer $[2,11,18]$.

A tumor-promoting inflammatory microenvironment is driven by interactions between the malignant cells, immune cells, and other stromal cells, which communicate through numerous growth factors, cytokines, and other locally active agents $[18,19]$. These factors are essential for tumor growth, progression, and metastasis $[11,20]$. In addition, some of the pro-inflammatory factors may exert effects that go beyond the local tumor, causing a state of systemic inflammation [11,21], which is strongly implicated as an important cause of cancer-associated morbidity, in terms of pain, fatigue, functional disability, anorexia, and cachexia, as well as reduced treatment response and poor survival $[5,6,22,23]$.

Interleukin-6 (IL-6) is an important proinflammatory cytokine produced particularly by macrophages but also by other stromal cells such as neutrophils, cancer-associated fibroblasts and endothelial cells, as well as some cancer cells [24]. IL-6 exerts its effects on many cells $[25,26]$ through its receptor IL-6R with the associated gp130 and downstream mechanisms where JAK-STAT3 is a major pathway [19, 27]. IL-6 has a main role in sustaining chronic inflammation [28], and it is a potent inducer of hepatic synthesis of acute phase proteins, including C-reactive protein (CRP) [29]. Furthermore, several lines of evidence implicate IL-6 as a promoting factor in cancer [30-33] and suggest that IL6 contributes to a chronic inflammatory and tumorigenic microenvironment in CRC [19,34]. There are also reports showing that high IL-6 is associated with poor prognosis in CRC [35].

Measurable systemic effects of inflammation have been termed systemic inflammatory response (SIR). Different blood measures for SIR have been proposed $[8,9,36,37]$. The relationship between these measures and tumorigenic inflammatory processes in CRC is not fully clarified. There is a need of further studies of the prognostic significance of different markers of SIR. The levels of SIR markers, such as the modified Glasgow Prognostic Score (mGPS), the derived neutrophil to lymphocyte ratio (dNLR), platelet levels, CRP levels, and high-sensitive CRP (hs-CRP) have all been found to predict cancer-specific survival $[8,37,38]$. Most of these studies come from cohorts of patients treated with curative surgery, and only a few reports focus on patients with metastatic cancer. It was recently reported that high hs-CRP levels predict poor survival in mCRC [38]. Little is known about the impact of inflammation in mutation subgroups in this cancer. The present study was based on a cohort from the NORDIC-VII study with patients receiving first-line treatment for $\mathrm{mCRC}$ [39]. The aim was to explore the prognostic role of serum IL-6 and CRP levels, in the total study population as well as in subgroups according to $R A S$ and $B R A F$ mutation status, and to study the value of prognostic inflammatory markers for use in daily clinical practice.

\section{RESULTS}

\section{Baseline characteristics}

Between May 2005 and October 2007, patients with untreated mCRC were enrolled in the NORDIC-VII study, randomized to first line treatment with standard Nordic FLOX, cetuximab and FLOX, or cetuximab combined with intermittent FLOX [39]. In the present study, the data were analyzed across the different treatment arms. Baseline demographics and clinical characteristics of the 393 patients included in this study are shown in Table 1.

Analysis regarding tumor burden and site of metastases in relation to IL- 6 and CRP show that the distribution of inflammatory markers was relatively similar in the different groups, see Supplementary Table 1.

\section{Overall prognostic value of IL-6 in $\mathrm{mCRC}$}

High pretreatment levels of serum IL-6 were strongly associated with impaired survival. Figure 1 shows that patients with high versus low IL-6 levels (dichotomized at median $5.6 \mathrm{pg} / \mathrm{ml}$ ) had a median PFS of 
Table 1: Baseline patient demographics and clinical characteristic, $n=393$

\begin{tabular}{|l|l|}
\hline Characteristics & Median (range) \\
\hline Age, years & Number (\%) \\
\hline & \\
\hline Sex & $237(60.3)$ \\
male & $156(39.7)$ \\
\hline Wemale & \\
0 & $255(64.9)$ \\
1 & $114(29.0)$ \\
2 & $24(6.1)$ \\
\hline Location & \\
colon & $233(59.3)$ \\
rectum & $160(40.7)$ \\
\hline No.of metastatic site & $123(31.3)$ \\
1 & $270(68.7)$ \\
\hline 1 & \\
\hline Primary tumor resected & $95(24.2)$ \\
no & $298(75.8)$ \\
\hline yes & $82(20.9)$ \\
\hline Liver only & $311(79.1)$ \\
\hline yes & \\
no & $212(53.9)$ \\
\hline Alkaline phosphatase & $181(46.1)$ \\
\hline normal & $42(10.7)$ \\
abnormal & \\
\hline Prior adjuvant chemotherapy & \\
\hline
\end{tabular}
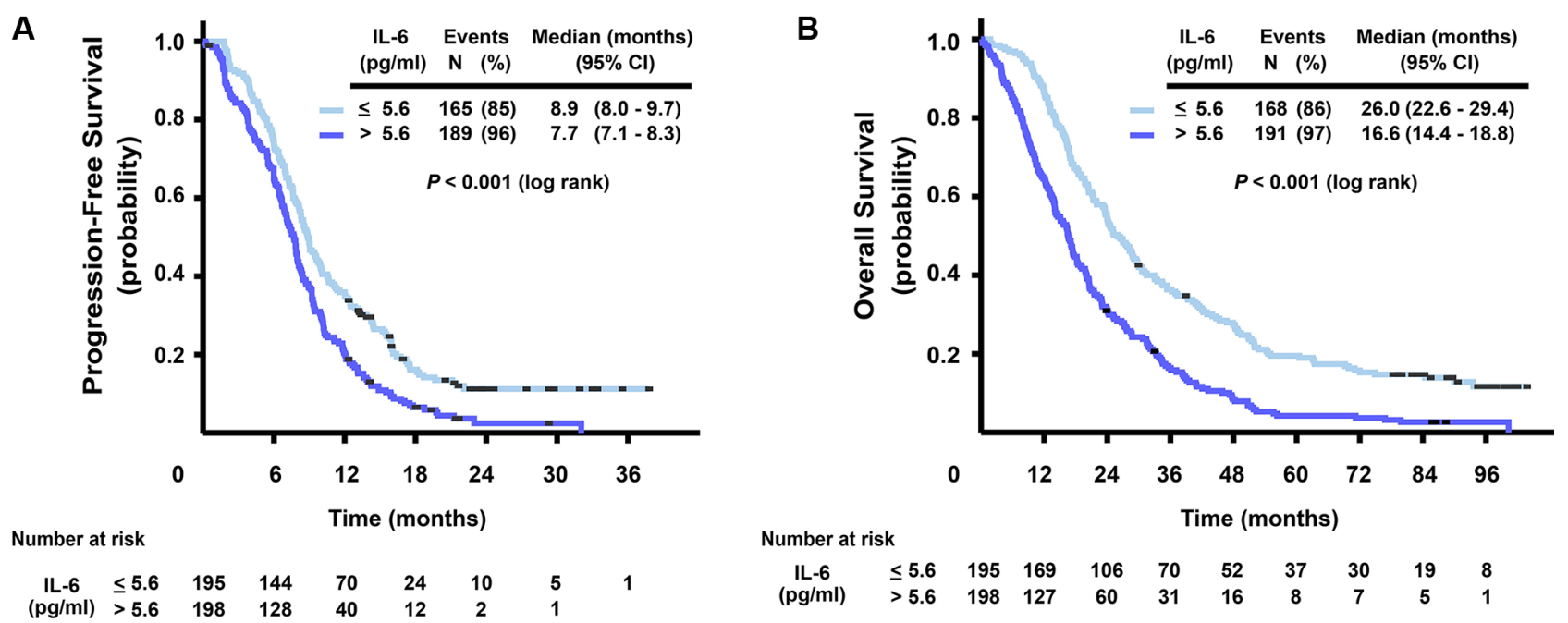

Figure 1: Kaplan-Meier curves for progression-free survival (A) and overall survival (B), stratified by IL-6 serum level (dichotomized at median, $\leq 5.6,>5.6 \mathrm{pg} / \mathrm{ml}$ ). 
7.7 versus 8.9 months, respectively $(\mathrm{HR}=1.54,95 \% \mathrm{CI}$ $1.25-1.91, P<0.001)$, and a median OS of 16.6 versus 26.0 months $(\mathrm{HR}=1.92,95 \% \mathrm{CI} 1.56-2.37, P<0.001)$. The prognostic role of baseline levels of IL-6 on OS was also confirmed in a model adjusting for other prognostic markers and clinical characteristics (CEA, mutation status, ALP and WHO performance status). Adding treatment arm or interaction between treatment arm and IL-6 in the analysis did not provide extra information. Sensitivity analysis with other cut-offs than the median for IL-6 gave essentially the same results.

\section{Prognostic role of IL-6 in subgroups according to $R A S$ and $B R A F$ mutation status}

The data indicated that the prognostic role of IL-6 differed depending on the $R A S$ and $B R A F$ mutation status, with a statistically significant interaction in unadjusted and adjusted analyses, $P=0.004$ (Table 2). There was a much larger relative reduction in survival associated with high IL-6 in the $B R A F$-mutated group, as analyzed with Cox regression for OS $(\mathrm{HR}=4.05,95 \%$ CI 2.13-7.71), compared to the double wild-type $(\mathrm{HR}=1.44,95 \% \mathrm{CI}$ $1.00-2.06)$ and the $R A S$-mutated groups $(\mathrm{HR}=1.23,95 \%$ CI 0.88-1.72). Median PFS and OS for patients with high versus low IL-6, sub-classified according to $R A S$ and $B R A F$ mutation status are summarized in Table 3.

\section{Comparison of inflammatory markers and correlation with IL-6}

The prognostic role of the different markers of SIR studied here, i.e. mGPS, dNLR, platelets, and CRP, in terms of PFS and OS, was examined. The results showed that for all these SIR markers high levels were associated with poor outcome, and no statistically significant differences in their prognostic value were detected (Table 4). Only CRP was used as a SIR biomarker in the further analyses. Supplementary Figure 1 shows a positive correlation between values of serum CRP and IL-6 ( $r=0.66, P<0.001)$, indicating that about $40 \%$ of the variability in the CRP values could be accounted for by IL-6. The frequency distribution of CRP and IL-6 levels was similar in the different mutation subgroups (Table 3). Neither were there any major differences in the distribution of platelets, dNLR, and mGPS overall or for the different subgroups, see Supplementary Table 2.

\section{Prognostic value of CRP}

High levels of CRP were associated with short survival. Figure 2 shows that in the four categories of baseline serum CRP level $(\leq 10,11-30,31-60$ and $>60$ $\mathrm{mg} / \mathrm{L}$ ), median PFS was 8.9, 7.6, 8.2, and 6.6 months, respectively (log rank test, $P<0.001$ ) and median OS was $24.3,20.6,17.1$, and 12.3 months, respectively (log rank test, $P<0.001)$. The prognostic role of baseline serum CRP in terms of OS was also confirmed in a model adjusted for other prognostic markers and clinical characteristics (CEA, mutation status, ALP and WHO performance status) (HR 1.16, 95\% CI 1.03-1.30, $P=0.015)$, see Supplementary Table 3. Adding treatment arm in the analysis gave no additional information.

Median PFS and OS for patients with different CRP levels according to mutation status are summarized in Table 3. OS for patients with CRP values under $10 \mathrm{mg} / \mathrm{L}$ compared to CRP values over $60 \mathrm{mg} / \mathrm{L}$ were 33.8 versus 12.8 months in the wild-type group, 20.5 versus 14.2 months in the $R A S$ mutated group and 14.1 versus 3.8 months in the $B R A F$ mutated group. Although these relationships between serum levels of CRP and treatment outcome largely followed the same pattern as for IL-6 in the subgroups of $R A S$ and $B R A F$ mutation status, the interaction between mutation status and different CRP levels was not statistically significant.

\section{Changes in CRP and IL-6 over time}

Having shown that baseline levels of both serum IL-6 and CRP have statistically significant impact on survival, we further explored whether changes in IL-6 and CRP over the first 8 weeks of treatment would improve the prognostic value of the markers. Mutation status did not significantly affect the distribution of change in either inflammatory marker. The distribution of change in CRP was also similar in the three arms, but the proportion of patients with a reduction in IL-6 was slightly higher in arm A (Supplementary Table 4). Several exploratory analyses with different measures of changes over time were performed. None of the models including changes in serum IL-6 or CRP over 8 weeks improved prediction of PFS or OS over models including baseline IL-6 or CRP only (Supplementary Table 5).

\section{DISCUSSION}

This study adds to the evidence of a role of inflammatory processes in cancer, as it demonstrates that high levels of inflammation biomarkers predict markedly impaired survival in a large cohort of patients with mCRC. Furthermore, it provides more results to support the involvement of IL-6 in tumor-promoting inflammation in this malignancy, and the data also suggest that IL-6 interacts differentially with the tumorigenic mechanisms of mutated $B R A F$ and $R A S$ in CRC. Finally, the study demonstrates that CRP, which is easily available in routine clinical practice, is a useful prognostic biomarker in this disease.

The role of IL-6 in inflammation and in the pathogenesis of various human diseases is well documented $[25,26,40]$. In cancer, IL-6 is produced by several cells in a tumor and can exert its pleiotropic effects 
Table 2: Multivariable cox regression analysis for OS including interaction term for IL-6 and $R A S$ and $B R A F$ mutation status in 364 patients

\begin{tabular}{|c|c|c|c|c|}
\hline \multirow{2}{*}{ Variable } & & \multicolumn{3}{|c|}{ Adjusted analysis, IL-6 } \\
\hline & & HR & $95 \% \mathrm{CI}$ & $P$-value \\
\hline Mutation status & $\begin{array}{c}\mathrm{IL}-6 \\
\mathrm{pg} / \mathrm{ml} \\
\end{array}$ & & & \\
\hline $\begin{array}{l}R A S / B R A F \mathrm{WT} \\
(n=154)\end{array}$ & $\begin{array}{l}\leq 5.8 \\
>5.8\end{array}$ & $\begin{array}{l}1 \\
1.44\end{array}$ & $1.00-2.06$ & \multirow{3}{*}{0.004} \\
\hline $\begin{array}{l}\text { RAS Mut } \\
(n=167)\end{array}$ & $\begin{array}{l}\leq 5.8 \\
>5.8\end{array}$ & $\begin{array}{l}1 \\
1.23\end{array}$ & $0.88-1.72$ & \\
\hline $\begin{array}{l}\text { BRAF Mut } \\
(n=43)\end{array}$ & $\begin{array}{l}\leq 5.8 \\
>5.8\end{array}$ & $\begin{array}{l}1 \\
4.05\end{array}$ & $2.13-7.71$ & \\
\hline $\begin{array}{l}\text { CEA mg/L } \\
<5(n=70) \\
\geq 5(n=294)\end{array}$ & & $\begin{array}{l}1 \\
1.68 \\
\end{array}$ & $1.23-2.30$ & $<0.001$ \\
\hline $\begin{array}{l}\text { ALP } \\
\text { Normal }(n=195) \\
\text { Abnormal }(n=169) \\
\end{array}$ & & $\begin{array}{l}1 \\
1.58 \\
\end{array}$ & $1.24-2.01$ & $<0.001$ \\
\hline $\begin{array}{l}\text { WHO performance status } \\
0(n=235) \\
1(n=105) \\
2(n=24)\end{array}$ & & $\begin{array}{l}1 \\
1.29 \\
2.70\end{array}$ & $\begin{array}{l}1.00-1.66 \\
1.71-4.26\end{array}$ & $\begin{array}{r}<0.001 \\
\\
\quad 0.048 \\
<0.001\end{array}$ \\
\hline
\end{tabular}

Abbreviations: Mut, mutant; WT, wild- type; OS, overall survival; CEA, Carcinoembryonic antigen; ALP, Alkaline phosphatase * interaction $P$.

on both malignant and stromal cells $[30,41]$. This is the case for both sporadic and inflammation-associated CRC $[7,19,30,34,41]$. In the present study of patients with $\mathrm{mCRC}$, we found that high serum concentrations of IL-6 were associated with markedly impaired prognosis.

Furthermore, the finding that a high level of IL-6 was associated with a particularly large relative reduction in survival in patients with mutated $B R A F$, unlike mutated $R A S$, is worth noting. Although the molecular explanation

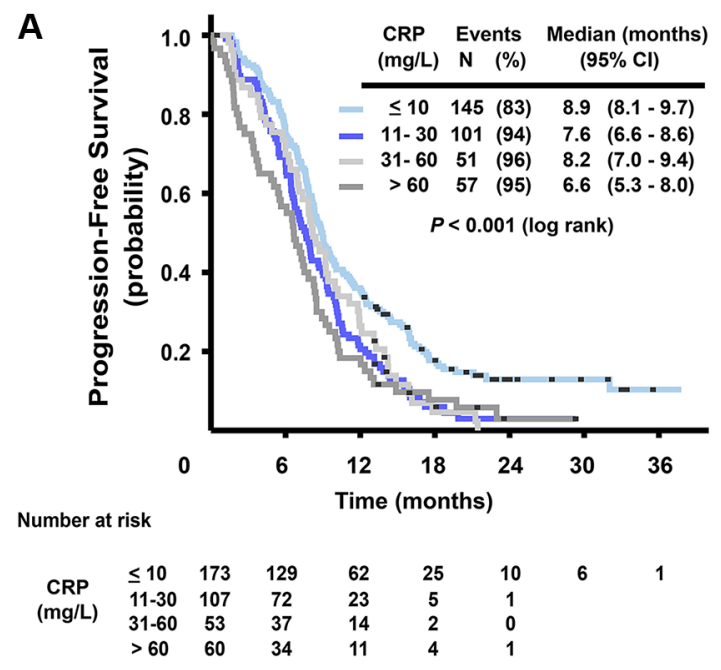

for this is not known, it might reflect differences in the way IL-6 interacts with the tumorigenic mechanisms activated by the mutated $B R A F$ and mutated $R A S$. The serine/threonine kinase BRAF, which is activated dramatically by the V600E mutation [42], is a selective activator of the MEK/ERK pathway, a major mediator of cell cycle entry. IL-6 primarily stimulates proinflammatory pathways, notably JAK/STAT signaling, which exerts several potentially tumor-promoting effects,

Figure 2: Kaplan-Meier curves for progression-free survival (A) and overall survival (B), stratified by CRP serum level $(\leq 10,11-30,31-60$ and $>60 \mathrm{mg} / \mathrm{L})$. 
Table 3: Median PFS and OS, subclassified according to $R A S$ and $B R A F$ mutation status in 393 patients

\begin{tabular}{|c|c|c|c|c|c|c|c|c|c|}
\hline & \multicolumn{6}{|c|}{ PFS } & \multicolumn{3}{|c|}{ OS } \\
\hline & & $\begin{array}{l}R A S / B R A F \\
\text { WT }\end{array}$ & & $\begin{array}{l}R A S \\
\text { Mut }\end{array}$ & & $\begin{array}{c}B R A F \\
\text { Mut }\end{array}$ & $\begin{array}{c}R A S / B R A F \\
\text { WT }\end{array}$ & $\begin{array}{l}R A S \\
\text { Mut }\end{array}$ & $\begin{array}{c}B R A F \\
\text { Mut }\end{array}$ \\
\hline & $n(\%)$ & $\begin{array}{c}\text { Median } \\
\text { (months) } \\
95 \% \mathrm{CI}\end{array}$ & $n(\%)$ & $\begin{array}{c}\text { Median } \\
\text { (months) } \\
95 \% \mathrm{CI}\end{array}$ & $n(\%)$ & $\begin{array}{c}\text { Median } \\
\text { (months) } \\
95 \% \mathrm{CI}\end{array}$ & $\begin{array}{c}\text { Median } \\
\text { (months) } \\
95 \% \mathrm{CI}\end{array}$ & $\begin{array}{c}\text { Median } \\
\text { (months) } \\
95 \% \mathrm{CI}\end{array}$ & $\begin{array}{c}\text { Median } \\
\text { (months) } \\
95 \% \mathrm{CI}\end{array}$ \\
\hline $\begin{array}{l}\text { IL-6, } \mathbf{p g} / \mathrm{ml} \\
\leq 5.6 \\
>5.6\end{array}$ & $\begin{array}{l}79(47.0) \\
89(53.0)\end{array}$ & $\begin{array}{l}10.9(8.5-13.3) \\
8.4(7.4-9.5) \\
P<0.001\end{array}$ & $\begin{array}{l}97(54.2) \\
82(45.8)\end{array}$ & $\begin{array}{l}8.2(7.5-8.8) \\
7.8(6.8-8.8) \\
P=0.364\end{array}$ & $\begin{array}{l}19(41.3) \\
27(58.7)\end{array}$ & $\begin{array}{l}9.0(3.6-14.3) \\
4.6(3.0-6.3) \\
P<0.001\end{array}$ & $\begin{array}{l}35.3(25.3-45.3) \\
20.5(18.8-22.3) \\
P<0.001\end{array}$ & $\begin{array}{l}23.4(19.3-27.5) \\
16.6(14.2-19.1) \\
P=0.002\end{array}$ & $\begin{array}{l}17.0(6.9-27.0) \\
6.9(4.7-9.2) \\
P<0.001\end{array}$ \\
\hline $\begin{array}{l}\mathbf{C R P}, \mathbf{m g} / \mathbf{L} \\
\leq 10 \\
11-30 \\
31-60 \\
>60\end{array}$ & $\begin{array}{l}69(41.1) \\
49(29.2) \\
26(15.5) \\
24(14.3)\end{array}$ & $\begin{array}{l}10.9(7.9-13.9) \\
9.3(8.2-10.4) \\
9.2(6.5-11.9) \\
7.3(5.6-9.0) \\
P=0.005\end{array}$ & $\begin{array}{l}83(46.4) \\
48(26.8) \\
20(11.2) \\
28(15.6)\end{array}$ & $\begin{array}{l}8.3(7.7-8.9) \\
6.7(5.6-7.9) \\
7.1(4.6-9.5) \\
6.8(4.7-9.0) \\
P=0.089\end{array}$ & $\begin{array}{r}21(45.7) \\
10(21.7) \\
7(15.2) \\
8(17.4)\end{array}$ & $\begin{array}{l}6.9(4.6-9.2) \\
5.4(2.7-8.1) \\
5.8(1.2-10.2) \\
1.8(0-4.5) \\
P=0.054\end{array}$ & $\begin{array}{l}33.8(26.2-41.4) \\
22.6(12.3-32.9) \\
20.5(15.4-25.6) \\
12.8(9.2-16.3) \\
P<0.001\end{array}$ & $\begin{array}{l}20.5(16.0-24.9) \\
20.6(14.8-26.4) \\
16.2(11.7-20.7) \\
14.2(5.2-23.1) \\
P<0.009\end{array}$ & $\begin{aligned} & 14.1(8.4-19.9) \\
& 8.1(5.1-11.1) \\
& 7.6(4.2-11.0) \\
& 3.8(2.1-5.5) \\
& P<0.008\end{aligned}$ \\
\hline
\end{tabular}

Abbreviations: PFS, progression-free survival; OS, overall survival; IL-6, Interleukin 6; CRP, C-reactive protein; WT, wild- type; Mut, mutant.

including angiogenesis and enhanced invasive capacity $[33,40]$. It is likely that these complementary mechanisms may form a basis for synergism. In contrast, mutated $R A S$ can mediate enhanced activity in several pathways [43], leading to stimulation not only of the ERK cascade but also the PI3K/Akt and other pathways, with downstream mechanisms that may enhance inflammatory processes, and it is conceivable that a pro-inflammatory stimulus from IL-6 may have a somewhat weaker impact on a $R A S$ driven malignancy.

A major aim of this study was to examine the prognostic potential of easily available markers of inflammation in mCRC. It was found that the level of CRP was a strong prognostic predictor in $\mathrm{mCRC}$, in agreement with data recently reported by others [38]. Regarding survival, CRP was an equally good marker as dNLR, mGPS and platelets. The median OS was 33.8 months in patients whose tumors were double wild-type and who had normal CRP and 12.8 months in the highest CRP group. Corresponding results for mutated $R A S$ and mutated $B R A F$ groups were 20.5 versus 14.2 and 14.1 versus 3.8 months, respectively. However, the interaction between $R A S$ or $B R A F$ mutation status and CRP value, unlike IL-6, was not statistically significant. This and the fact that the correlation between IL-6 and CRP, although statistically significant, was not very strong, indicate that CRP likely reflects a broader measure of the inflammatory status than IL-6.

The marked difference in OS for high versus low IL-6 or CRP despite relatively small differences in PFS is consistent with data indicating a special role of inflammation in advanced and cachectic cancer [5, 23]. Baseline serum IL- 6 and CRP levels were better predictors of survival than changes in IL-6 and CRP levels during treatment. This probably reflects distinct phenotypes from early stages of the tumor development.
The inflammatory burden is likely responsible for clinical effects such as weight loss and poor performance status $[9,22,23]$. Like some of the other established markers of SIR, CRP has the advantage of being inexpensive, and it can be measured routinely both in daily clinical practice and in study settings, making it easily accessible, and, in addition, it is also readily and precisely quantifiable [36]. Since increasing CRP values confer an increasingly worse prognosis independent of other wellknown prognostic markers, CRP adds important clinical value. Combining information on CRP and mutation status provides improved prognostic information that may guide treatment decisions concerning the need for aggressive first-line treatment for some patients. On the other hand, some patients with $B R A F$ mutation combined with elevated CRP have a very poor prognosis and might have limited benefit from chemotherapy.

The main strength of this study is that it is large and analyzes multiple markers of SIR in a cohort of prospectively collected data from patients with mCRC. Most previous reports of systemic inflammation come from cohorts of cancer patients treated with surgery, and only a few reports focus on patients with unresectable metastatic cancer. The size of this study provides the opportunity to compare different markers of SIR and also allows analysis of the prognostic role of IL-6 and inflammation as related to mutation status. However, there are also several limitations, as not all variables were available for all patients, and data on possible ongoing infections are lacking.

In conclusion, serum IL-6 and CRP are good prognostic biomarkers in patients with $\mathrm{mCRC}$ independent of the RAS and BRAF mutation status. The effect of IL-6 was particularly pronounced in patients with $B R A F$ mutation. Combining the prognostic information of CRP and IL-6 with knowledge of the $R A S$ and $B R A F$ mutation 
Table 4: Prognostic information in terms of PFS and OS of different markers of systemic inflammatory response (SIR) in 374 patients

\begin{tabular}{|c|c|c|c|c|c|c|c|}
\hline & \multirow[b]{2}{*}{$n(\%)$} & \multicolumn{3}{|c|}{ PFS } & \multicolumn{3}{|c|}{ OS } \\
\hline & & HR & $95 \% \mathrm{CI}$ & $P$-value & HR & $95 \% \mathrm{CI}$ & $P$-value \\
\hline $\begin{array}{l}\mathrm{CRP}(\mathrm{mg} / \mathrm{L}) \\
\leq 10 \\
11-30 \\
31-60 \\
>60\end{array}$ & $\begin{array}{r}165(44.1) \\
100(26.7) \\
51(13.6) \\
58(15.5)\end{array}$ & $\begin{array}{l}1 \\
1.63 \\
1.45 \\
1.82\end{array}$ & $\begin{array}{l}1.25-2.12 \\
1.04-2.01 \\
1.33-2.49\end{array}$ & $\begin{array}{r}<0.001 \\
<0.001 \\
0.027 \\
<0.001\end{array}$ & $\begin{array}{l}1 \\
1.38 \\
1.88 \\
2.45\end{array}$ & $\begin{array}{l}1.06-1.79 \\
1.35-2.62 \\
1.79-3.35\end{array}$ & $\begin{array}{r}<0.001 \\
\\
\\
0.016 \\
<0.001 \\
<0.001\end{array}$ \\
\hline $\begin{array}{l}\text { Platelets }\left(10^{9} / \mathrm{L}\right) \\
\leq 400 \\
>400\end{array}$ & $\begin{array}{l}266(71.1) \\
108(28.9)\end{array}$ & $\begin{array}{l}1 \\
1.60\end{array}$ & $1.27-2.02$ & $<0.001$ & $\begin{array}{l}1 \\
1.85\end{array}$ & $1.47-2.34$ & $<0.001$ \\
\hline $\begin{array}{l}\text { mGPS } \\
0 \\
1 \\
2\end{array}$ & $\begin{array}{r}165(44.1) \\
166(44.4) \\
43(11.5)\end{array}$ & $\begin{array}{l}1 \\
1.55 \\
1.99\end{array}$ & $\begin{array}{l}1.23-1.95 \\
1.40-2.81\end{array}$ & $\begin{array}{l}<0.001 \\
<0.001 \\
<0.001\end{array}$ & $\begin{array}{l}1 \\
1.60 \\
2.16\end{array}$ & $\begin{array}{l}1.27-2.01 \\
1.52-3.06\end{array}$ & $\begin{array}{l}<0.001 \\
<0.001 \\
<0.001\end{array}$ \\
\hline $\begin{array}{l}\text { dNLR } \\
\leq 2.1 \\
>2.1\end{array}$ & $\begin{array}{l}187(50.0) \\
187(50.0)\end{array}$ & $\begin{array}{l}1 \\
1.56\end{array}$ & $1.25-1.93$ & $<0.001$ & $\begin{array}{l}1 \\
1.68\end{array}$ & $1.35-2.08$ & $<0.001$ \\
\hline
\end{tabular}

Abbreviations: CRP, C-reactiv protein; mGPS, Modified Glasgow Prognostic Score: $0=\mathrm{CRP} \leq 10 \mathrm{mg} / \mathrm{L}$ (independent of the albumin level), $1=\mathrm{CRP}>10 \mathrm{mg} / \mathrm{L}$ and albumin $\geq 35 \mathrm{~g} / \mathrm{L}, 2=\mathrm{CRP}>10 \mathrm{mg} / \mathrm{L}$ and albumin $<35 \mathrm{~g} / \mathrm{L} ; \mathrm{dNLR}$, Derived Neutrophil to Lymphcyte Ratio.

status may help in treatment decisions. It is conceivable that patients with high serum IL-6 might benefit from treatment interrupting the inflammation, and drugs targeting the IL-6/IL-6R axis might be a future treatment option in CRC $[6,34,44,45]$.

\section{MATERIALS AND METHODS}

\section{Patients}

The randomized NORDIC-VII study [39] investigated the effects of combining cetuximab with a regimen of bolus 5-flourouracil (5-FU)/folinic acid (FA) and oxaliplatin (Nordic FLOX) [46] in first-line therapy of mCRC. Patients were randomly assigned to receive standard Nordic FLOX, cetuximab and FLOX, or cetuximab combined with intermittent FLOX. Since there was no statistically significant difference in outcome between the treatment arms, neither in the original analysis [39] nor in subsequent updated overall survival data until April 30, 2014 (unpublished data), the present study used the whole patient population across the different treatments in NORDIC-VII.

$R A S$ and $B R A F$ mutation status was available for 393 patients. Of these 364 patients were eligible for the multivariable analysis of clinical and prognostic markers, whereas 374 patients were eligible for the comparison of different markers of SIR with available albumin, CRP, platelets, neutrophils and leukocytes at baseline. Measures of both serum IL- 6 and CRP at baseline and at week 8 were available for 393 and 275 patients, respectively. Mutation status (RAS, RAF, double wild-type) was obtained for the whole study population.

\section{Collection of blood samples and IL-6 measurement}

WBC, ANC, platelet count and hemoglobin were measured at baseline and before each treatment cycle. Albumin was analysed at baseline and every second cycle and CRP was measured at baseline, after one week and then before every cycle for four cycles and every fourth cycle thereafter. The analyses were conducted according to current practice at each participating hospital. Freshfrozen serum/plasma samples were collected at baseline, after the first week of cycle 1, after the second week of cycle 1 and after the second week of cycle 4. Serum concentration of IL-6 was determined in serum samples stored at minus $80^{\circ} \mathrm{C}$ by a commercially available human IL-6 high-sensitive enzyme-linked immunosorbent assay (ELISA, Quantikine HS, high sensitive, R\&D Systems, Abingdon, Oxon, UK) [47].

\section{Mutation analyses of $K R A S, N R A S$ and $B R A F$}

Genomic DNA was extracted from formalin-fixed paraffin-embedded (FFPE) $10 \mu \mathrm{m}$ tissue sections with $65 \%$ to $70 \%$ (median) tumour cells using QIAamp DNA 
Micro Kit (Cat.56304, Quiagen). Tumour DNA was screened for the presence of the KRAS mutations Q61H, Q61L, Q61R, K117X (K117N 351A > C, K117N 351A > T, K117R, K117E) and A146X (A146T, A146P, A146V) using the KRAS Mutation Analysis Kit for Real-Time PCR (exons 2, 3 and 4) by EntroGen. The NRAS mutations G12C, G12D, G12S, G13V, G13R, Q61K, Q61R, Q61L, Q61H and A146T were analyzed using the NRAS Mutation Analysis kit (EntroGen). The mutation detection assays and the analysis of the results were performed in accordance with the manufacturer's instructions. Input in the $K R A S$ and $N R A S$ assays were $10 \mathrm{ng}$ and $20 \mathrm{ng}$ DNA, respectively. Analyses for the $B R A F \mathrm{~V} 600 \mathrm{E}$ mutation was performed as described by Hamfjord et al. [48]

\section{Markers of SIR}

dNLR, platelet counts, mGPS, and CRP were chosen as clinically useful markers of SIR. dNLR was applied with the assumption that white blood cell counts is made up primarily of lymphocytes and neutrophils, and that the white cell count minus neutrophil count would be quite similar to the lymphocyte count [37]. Separate analyses of the prognostic effect of each different inflammatory marker on PFS and OS were performed. Patients were grouped into four CRP categories $(\leq 10,11-30,31-60,>$ $60 \mathrm{mg} / \mathrm{L}$ ), based upon current reference cut-off values in colon cancer [36]. dNLR was dichotomized at the median value 2.1, as no consensus regarding cut-off values exists in the literature, but in accordance with previous publications [37]. Platelet counts were dichotomized at below or above $400 \cdot 109 /$ L. mGPS was classified from 0-2, 0 defined as $\mathrm{CRP} \leq 10 \mathrm{mg} / \mathrm{L}$ (independent of the albumin level), 1 defined as CRP $>10 \mathrm{mg} / \mathrm{L}$ and albumin $\geq 35 \mathrm{~g} / \mathrm{L}$, and 2 defined as CRP $>10 \mathrm{mg} / \mathrm{L}$ and albumin $<35 \mathrm{~g} / \mathrm{L}$ [49]. IL-6 levels were dichotomized at the median $5.6 \mathrm{pg} / \mathrm{ml}$, as no consensus exists in the literature concerning cut-off value [30]. Reported median serum IL-6 in healthy subjects was $1.4 \mathrm{pg} / \mathrm{ml}$ [47]. The results of IL-6 and mutation analyses are presented in accordance with REMARK (Reporting Recommendations for Tumor Marker Prognostic Studies) guidelines [50]. The remaining analyses were conducted according to current practice at each participating hospital.

\section{Ethics}

The NORDIC-VII study (http://clinicaltrials.gov/ show/NCT00145314) was approved by the national ethics committees and governmental authorities in each country and conducted in accordance with the Declaration of Helsinki. All patients gave written informed consent.

\section{Statistical analysis}

The statistical analyses were performed using IBM SPSS (version 18.0. Chicago: SPSS Inc.). Demographic data were described with median and range (continuous variables) and with proportion and percentages (categorical variables). The prognostic values of different categories of IL-6 and CRP values were assesed by Kaplan-Meier plots, log-rank test, and Cox proportional hazards model. Separate analyses of the effect of IL-6, CRP, CEA, ALP, WHO performance status, mutation status, platelets, WBC, ANC, metastatic site, number of metastatic sites, sex, tumor location, treatment arm and age were performed. Only variables statistically significant in these analyses were included in the multivariable analyses and models were restricted to include statistically significant variables only. Correlation between IL-6 and CRP was estimated with Pearson's r using log-transformed values to ensure an approximately linear association. An interaction term was included in the Cox model to explore the effect of mutation status on the prognostic effect of IL-6 and CRP, respectively. Several different measures of change in CRP and IL- 6 over 8 weeks; absolute and relative difference, as well as various categorizations were explored and compared using landmark analysis. Model fit was compared by likelihood ratio tests, and the model finally chosen was the one resulting in the best fit.

\section{ACKNOWLEDGMENTS AND FUNDING}

The NORDIC-VII study was supported by Merck KGaA, Darmstadt, Germany and Sanofi, Oslo, Norway.

This work was supported by The Norwegian Cancer Society and The Swedish Cancer Society.

\section{CONFLICTS OF INTEREST}

The authors declare no conflicts of interest

\section{REFERENCES}

1. Jemal A, Bray F, Center MM, Ferlay J, Ward E, Forman D. Global cancer statistics. CA Cancer J Clin. 2011; 61:69-90.

2. Tlsty TD, Coussens LM. Tumor stroma and regulation of cancer development. Annu Rev Pathol. 2006; 1:119-150.

3. Mantovani A, Allavena P, Sica A, Balkwill F. Cancer-related inflammation. Nature. 2008; 454:436-444.

4. Grivennikov SI, Greten FR, Karin M. Immunity, inflammation, and cancer. Cell. 2010; 140:883-899.

5. Tsoli M, Robertson G. Cancer cachexia: malignant inflammation, tumorkines, and metabolic mayhem. Trends Endocrinol Metab. 2013; 24:174-183.

6. Diakos CI, Charles KA, McMillan DC, Clarke SJ. Cancerrelated inflammation and treatment effectiveness. Lancet Oncol. 2014; 15:e493-503.

7. Wang K, Karin M. Tumor-Elicited Inflammation and Colorectal Cancer. Adv Cancer Res. 2015; 128:173-196.

8. Proctor MJ, Morrison DS, Talwar D, Balmer SM, Fletcher CD, O'Reilly DS, Foulis AK, Horgan PG, 
McMillan DC. A comparison of inflammation-based prognostic scores in patients with cancer. A Glasgow Inflammation Outcome Study. Eur J Cancer. 2011; 47:2633-2641.

9. Roxburgh CS, McMillan DC. Role of systemic inflammatory response in predicting survival in patients with primary operable cancer. Future Oncol. 2010; 6:149-163.

10. Stratton MR, Campbell PJ, Futreal PA. The cancer genome. Nature. 2009; 458:719-724.

11. Quail DF, Joyce JA. Microenvironmental regulation of tumor progression and metastasis. Nat Med. 2013; 19:1423-1437.

12. Bissell MJ, Radisky D. Putting tumours in context. Nat Rev Cancer. 2001; 1:46-54.

13. Hanahan D, Weinberg RA. Hallmarks of cancer: the next generation. Cell. 2011; 144:646-674.

14. de Visser KE, Eichten A, Coussens LM. Paradoxical roles of the immune system during cancer development. Nat Rev Cancer. 2006; 6:24-37.

15. Gajewski TF, Schreiber H, Fu YX. Innate and adaptive immune cells in the tumor microenvironment. Nat Immunol. 2013; 14:1014-1022.

16. Galon J, Mlecnik B, Bindea G, Angell HK, Berger A, Lagorce C, Lugli A, Zlobec I, Hartmann A, Bifulco C, Nagtegaal ID, Palmqvist R, Masucci GV, et al. Towards the introduction of the 'Immunoscore' in the classification of malignant tumours. J Pathol. 2014; 232:199-209.

17. Kitamura T, Qian BZ, Pollard JW. Immune cell promotion of metastasis. Nat Rev Immunol. 2015; 15:73-86.

18. Hanahan D, Coussens LM. Accessories to the crime: functions of cells recruited to the tumor microenvironment. Cancer Cell. 2012; 21:309-322.

19. West NR, McCuaig S, Franchini F, Powrie F. Emerging cytokine networks in colorectal cancer. Nat Rev Immunol. 2015; 15:615-629.

20. Wan L, Pantel K, Kang Y. Tumor metastasis: moving new biological insights into the clinic. Nat Med. 2013; 19:1450-1464.

21. Lippitz BE. Cytokine patterns in patients with cancer: a systematic review. Lancet Oncol. 2013; 14:e218-228.

22. Park JH, Watt DG, Roxburgh CS, Horgan PG, McMillan DC. Colorectal Cancer, Systemic Inflammation, and Outcome: Staging the Tumor and Staging the Host. Ann Surg. 2015;00:1-11.

23. Laird BJ, McMillan DC, Fayers P, Fearon K, Kaasa S, Fallon MT, Klepstad P. The systemic inflammatory response and its relationship to pain and other symptoms in advanced cancer. Oncologist. 2013; 18:1050-1055.

24. Akira S, Taga T, Kishimoto T. (1993). Interleukin-6 in Biology and Medicine. In: Frank JD, ed. Adv Immunol: Academic Press, pp. 1-78.

25. Calabrese LH, Rose-John S. IL-6 biology: implications for clinical targeting in rheumatic disease. Nat Rev Rheumatol. 2014; 10:720-727.
26. Tanaka T, Narazaki M, Kishimoto T. IL-6 in inflammation, immunity, and disease. Cold Spring Harb Perspect Biol. 2014; 6:a016295.

27. Tanaka T, Kishimoto T. The biology and medical implications of interleukin-6. Cancer Immunol Res. 2014; 2:288-294.

28. Gabay C. Interleukin-6 and chronic inflammation. Arthritis Res Ther. 2006; 82:S3.

29. Rhodes B, Furnrohr BG, Vyse TJ. C-reactive protein in rheumatology: biology and genetics. Nat Rev Rheumatol. 2011; 7:282-289.

30. Knupfer H, Preiss R. Serum interleukin-6 levels in colorectal cancer patients--a summary of published results. Int J Colorectal Dis. 2010; 25:135-140.

31. Grivennikov S, Karin E, Terzic J, Mucida D, Yu GY, Vallabhapurapu S, Scheller J, Rose-John S, Cheroutre H, Eckmann L, Karin M. IL-6 and Stat3 are required for survival of intestinal epithelial cells and development of colitis-associated cancer. Cancer Cell. 2009; 15:103-113.

32. Chung YC, Chang YF. Serum interleukin-6 levels reflect the disease status of colorectal cancer. J Surg Oncol. 2003; $83: 222-226$.

33. Taniguchi K, Karin M. IL-6 and related cytokines as the critical lynchpins between inflammation and cancer. Semin Immunol. 2014; 26:54-74.

34. Waldner MJ, Neurath MF. Master regulator of intestinal disease: IL-6 in chronic inflammation and cancer development. Semin Immunol. 2014; 26:75-79.

35. Xu J, Ye Y, Zhang H, Szmitkowski M, Mäkinen MJ, Li P, Xia D, Yang J, Wu Y, Wu H. Diagnostic and Prognostic Value of Serum Interleukin-6 in Colorectal Cancer. Medicine. 2016; 95:e2502.

36. Kersten C, Louhimo J, Algars A, Lahdesmaki A, Cvancerova M, Stenstedt K, Haglund C, Gunnarsson U. Increased C-reactive protein implies a poorer stage-specific prognosis in colon cancer. Acta Oncol. 2013; 52:1691-1698.

37. Proctor MJ, McMillan DC, Morrison DS, Fletcher CD, Horgan PG, Clarke SJ. A derived neutrophil to lymphocyte ratio predicts survival in patients with cancer. Br J Cancer. 2012; 107:695-699.

38. Casadei Gardini A, Carloni S, Scarpi E, Maltoni P, Dorizzi RM, Passardi A, Frassineti GL, Cortesi P, Giannini MB, Marisi G, Amadori D, Lucchesi A. Prognostic role of serum concentrations of high-sensitivity C-reactive protein in patients with metastatic colorectal cancer: results from the ITACa trial. Oncotarget. 2016; 7:10193-10202. doi: 10.18632/oncotarget.7166.

39. Tveit KM, Guren T, Glimelius B, Pfeiffer P, Sorbye H, Pyrhonen S, Sigurdsson F, Kure E, Ikdahl T, Skovlund E, Fokstuen T, Hansen F, Hofsli E, et al. Phase III trial of cetuximab with continuous or intermittent fluorouracil, leucovorin, and oxaliplatin (Nordic FLOX) versus FLOX alone in first-line treatment of metastatic colorectal cancer: the NORDIC-VII study. J Clin Oncol. 2012; 30:1755-1762. 
40. Mauer J, Denson JL, Bruning JC. Versatile functions for IL-6 in metabolism and cancer. Trends Immunol. 2015; 36:92-101.

41. Guthrie GJ, Roxburgh CS, Richards CH, Horgan PG, McMillan DC. Circulating IL-6 concentrations link tumour necrosis and systemic and local inflammatory responses in patients undergoing resection for colorectal cancer. Br J Cancer. 2013; 109:131-137.

42. Michaloglou C, Vredeveld LC, Mooi WJ, Peeper DS. $\mathrm{BRAF}(\mathrm{E} 600)$ in benign and malignant human tumours. Oncogene. 2008; 27:877-895.

43. Rajalingam K, Schreck R, Rapp UR, Albert S. Ras oncogenes and their downstream targets. Biochim Biophys Acta. 2007; 1773:1177-1195.

44. Waldner MJ, Foersch S, Neurath MF. Interleukin-6--a key regulator of colorectal cancer development. Int J Biol Sci. 2012; 8:1248-1253.

45. Yao X, Huang J, Zhong H, Shen N, Faggioni R, Fung M, Yao Y. Targeting interleukin-6 in inflammatory autoimmune diseases and cancers. Pharmacol Ther. 2014; 141:125-139.

46. Sorbye H, Glimelius B, Berglund A, Fokstuen T, Tveit KM, Braendengen M, Ogreid D, Dahl O. Multicenter phase II study of Nordic fluorouracil and folinic acid bolus schedule combined with oxaliplatin as first-line treatment of metastatic colorectal cancer. J Clin Oncol. 2004; 22:31-38.

47. Knudsen LS, Christensen IJ, Lottenburger T, Svendsen MN, Nielsen HJ, Nielsen L, Horslev-Petersen K, Jensen JE, Kollerup G, Johansen JS. Pre-analytical and biological variability in circulating interleukin 6 in healthy subjects and patients with rheumatoid arthritis. Biomarkers. 2008; 13:59-78.

48. Hamfjord J, Stangeland AM, Skrede ML, Tveit KM, Ikdahl T, Kure EH. Wobble-enhanced ARMS method for detection of KRAS and BRAF mutations. Diagn Mol Pathol. 2011; 20:158-165.

49. McMillan DC, Crozier JE, Canna K, Angerson WJ, McArdle CS. Evaluation of an inflammation-based prognostic score (GPS) in patients undergoing resection for colon and rectal cancer. Int J Colorectal Dis. 2007; 22:881886.

50. Altman DG, McShane LM, Sauerbrei W, Taube SE. Reporting Recommendations for Tumor Marker Prognostic Studies (REMARK): explanation and elaboration. PLoS Med. 2012; 9:e1001216. 